\title{
INFLUENCE OF ABRASIVE MASS FRACTIONAL COMPOSITION ON DEPOSITED METAL WEAR RESISTANCE
}

\author{
V.V. PEREMITKO ${ }^{1}$ and V.D. KUZNETSOV ${ }^{2}$ \\ ${ }^{1}$ Dneprodzerzhinsk State Technical University \\ 2 Dneprostroevskaya Str., 51918, Dneprodzerzhinsk, Ukraine. E-mail: welding@dstu.ua \\ ${ }^{2}$ NTUU «Kiev Polytechnic Institute» \\ 37 Pobeda Ave., 03056, Kiev, Ukraine
}

\begin{abstract}
Abrasive wear of samples, surfaced with Sv-08G2S and Np-65 solid wires, using a mixture of fused and alloying agglomerated fluxes was studied. It is shown that selection of metal composition for surfacing parts of machines operating under abrasive wear conditions should be performed allowing for granulometric composition of abrasive medium. Values of optimum chemical and phase composition of metal recommended for surfacing parts of this type are given. Hardness values and ratios of its values for two contacting processed surfaces of parts have been determined, which allow part service life to be extended under the condition of allowing for abrasive granulometric composition. 7 Ref., 2 Tables, 4 Figures.
\end{abstract}

Keywords: arc surfacing, deposited metal, phase composition, abrasive wear, abrasive granulometric composition, wear resistance

Many parts of road-construction and agricultural machinery fail as a result of abrasive wear. One of the important factors in this process is wearing ability of treated soils, technological mixtures, etc. The above characteristic is determined by hardness, dimensions and shape of abrasive, degree of fastening of its particles, the hardness and shape of which determine the nature of fracture of surface layer of parts - microcutting or fatigue fracture as a result of multiple redeformation [1, 2].

General principles of alloying deposited metal, designed for restoration and hardening of parts operating under the conditions of different types of abrasive wear, have been quite completely formulated [3-6]. It should be noted, however, that these studies practically did not give any attention to the problem of influence of abrasive mass fractional composition on surfaced part wear resistance. Therefore, the objective of this work was investigation of the influence of abrasive fractional composition on deposited metal wear resistance.

Welding wire Sv-08G2S (GOST 2246-70) and surfacing wire Np-65 (GOST 10543-75), fused flux AN-348A and agglomerated alloying fluxes ANK-18 and ANK-19 were used in the investigations. Metal, deposited with low-carbon wire Sv-08G2S and ANK-18 flux, has chemical composition corresponding to steel 30Kh3G1,

(C) V.V. PEREMITKO and V.D. KUZNETSOV, 2015 and that deposited with ANK-19 flux has the composition of steel 60Kh4GS [7].

Test samples were cut out of surfaced cylindrical hollow billet $200 \mathrm{~mm}$ long (outer diameter of 36 , inner diameter of $16 \mathrm{~mm}$ ). Billets were surfaced in 3-4 layers up to achievement of billet outer diameter of $50 \mathrm{~mm}$. Modes of sample surfacing using flux mixture were as follows: $1.2 \mathrm{~mm}$ wire diameter; 160-180 A current; 27$28 \mathrm{~V}$ voltage; surfacing pitch of $3 \mathrm{~mm}$; surfacing speed of $24-33$ and $27-38 \mathrm{~m} / \mathrm{h}$.

Rollers of $10 \mathrm{~mm}$ thickness were cut out of surfaced billets. The roller outer processed surface was polished up to $45 \mathrm{~mm}$ diameter. Data on composition of deposited layers and their hardness are given in Table 1.

Wear resistance investigations were conducted by roller-roller schematic in MI-1M machine. Roller press-down force was $1 \mathrm{kN}$, roller rotation speed was approximately $200 \mathrm{rpm}$, duration of one test was $2 \mathrm{~h}$. Abrasive was quartz sand, which was fed through skeep into the gap between the rollers in fractions of different granulometric composition, with the ability to adjust the sand flow rate. Samples were weighed before and after testing in laboratory scales with $0.0001 \mathrm{~g}$ accuracy. Data on sample testing for wear with and without the abrasive are given in Table 2. It is found that wear of rollers surfaced with Sv-08G2S wire at testing without abrasive changes from 0.013 (experiment 4, upper roller) to $0.053 \mathrm{~g}$ (experiment 1, lower roller).

At application of Np-65 wire, roller wear decreases even more significantly at increase of 
INDUSTRIAL

Table 1. Deposited metal characteristics

\begin{tabular}{|c|c|c|c|c|c|c|c|c|}
\hline \multirow{2}{*}{$\begin{array}{c}\text { Exp. } \\
\text { number }\end{array}$} & \multirow{2}{*}{ Wire grade } & \multirow{2}{*}{ Flux, flux mixture } & \multicolumn{5}{|c|}{ Deposited metal chemical composition, wt.\% } & \multirow{2}{*}{$H B$} \\
\hline & & & $\mathrm{C}$ & $\mathrm{Mn}$ & $\mathrm{Si}$ & $\mathrm{Cr}$ & $\mathrm{Ni}$ & \\
\hline 1 & \multirow[t]{5}{*}{ Sv-08G2S } & AN-348A & 0.06 & 2.11 & 0.93 & 0.04 & 0.07 & 170 \\
\hline 2 & & AN-348A $+25 \%$ of ANK- 18 & 0.12 & 2.37 & 0.77 & 0.70 & 0.13 & 220 \\
\hline 3 & & AN-348A $+50 \%$ of ANK- 18 & 0.17 & 2.35 & 0.63 & 1.49 & 0.09 & 283 \\
\hline 4 & & AN-348A $+75 \%$ of ANK- 18 & 0.22 & 3.14 & 0.60 & 1.57 & 0.13 & 367 \\
\hline 5 & & ANK-18 & 0.37 & 2.88 & 0.39 & 3.18 & 0.11 & 409 \\
\hline 6 & \multirow[t]{5}{*}{ Np-65 } & AN-348A & 0.34 & 1.22 & 0.59 & 0.05 & 0.08 & 230 \\
\hline 7 & & AN-348A $+25 \%$ of ANK- 18 & 0.29 & 2.04 & 0.48 & 0.98 & 0.07 & 245 \\
\hline 8 & & AN-348A $+50 \%$ of ANK- 18 & 0.29 & 1.87 & 0.37 & 1.19 & 0.07 & 332 \\
\hline 9 & & AN-348A $+75 \%$ of ANK- 18 & 0.43 & 2.09 & 0.28 & 1.57 & 0.12 & 417 \\
\hline 10 & & ANK-18 & 0.63 & 1.20 & 0.29 & 2.57 & 0.08 & 547 \\
\hline
\end{tabular}

Table 2. Surfaced sample mass loss after wear testing

\begin{tabular}{|c|c|c|c|c|c|c|c|c|c|c|}
\hline \multirow{3}{*}{$\begin{array}{l}\text { Exp. } \\
\text { number }\end{array}$} & \multicolumn{10}{|c|}{ Roller wear, $\mathrm{g}$, depending on abrasive fraction, $\mathrm{mm}$} \\
\hline & \multicolumn{2}{|c|}{ Without abrasive } & \multicolumn{2}{|c|}{0.315} & \multicolumn{2}{|c|}{0.4} & \multicolumn{2}{|c|}{0.63} & \multicolumn{2}{|c|}{1} \\
\hline & Lower roller & Upper roller & Lower roller & Upper roller & Lower roller & Upper roller & Lower roller & Upper roller & Lower roller & Upper roller \\
\hline 1 & 0.053 & 0.010 & 0.340 & 0.728 & 0.674 & 0.621 & 1.577 & 2.349 & 0.344 & 0.318 \\
\hline 2 & 0.043 & 0.048 & 0.470 & 0.780 & 1.025 & 0.971 & 0.227 & 0.167 & 0.230 & 0.284 \\
\hline 3 & 0.035 & 0.071 & 0.174 & 0.145 & 0.953 & 0.801 & 0.762 & 0.837 & 0.134 & 0.136 \\
\hline 4 & 0.021 & 0.013 & 0.143 & 0.103 & 0.678 & 0.590 & 0.735 & 0.701 & 0.219 & 0.146 \\
\hline 5 & 0.023 & 0.024 & Spallation & Spallation & Spallation & Spallation & Spallation & Spallation & Spallation & Spallation \\
\hline 6 & 0.006 & 0.010 & 1.078 & 1.059 & 2.836 & 2.780 & 0.147 & 0.125 & 0.404 & 0.486 \\
\hline 7 & 0.046 & 0.029 & 0.851 & 0.790 & 1.440 & 1.253 & 0.978 & 0.886 & 0.317 & 0.243 \\
\hline 8 & 0.058 & 0.019 & 1.183 & 1.158 & 0.960 & 1.050 & 0.718 & 0.729 & 0.244 & 0.259 \\
\hline 9 & 0.079 & 0.050 & 0.376 & 0.417 & 0.773 & 0.838 & 0.869 & 0.840 & 0.345 & 0.485 \\
\hline 10 & 0.035 & 0.108 & 1.191 & 0.148 & 0.705 & 0.544 & 0.796 & 0.832 & 0.309 & 0.226 \\
\hline
\end{tabular}

layer alloying level, and it also reaches a minimum for metal deposited only with alloying flux ANK-18 (reduction of upper and lower roller wear in this case by 11 and 6 times, respectively, experiments $6-10$ ).

In the case of feeding abrasive of $0.315 \mathrm{~mm}$ fraction the greatest weight loss is shown by rollers surfaced with Np-65 wire (experiment 8), and the smallest weight loss is found in those surfaced with Sv-08G2S wire (experiment 4). At testing with abrasive of $0.4 \mathrm{~mm}$ fraction the smallest wear is observed in rollers, surfaced with $\mathrm{Sv}$ 08G2S wire using AN-348A flux (minimum alloying, experiment 1) or using a mixture of fluxes with $75 \%$ ANK-18 fraction in it (experiment 4).

Testing with abrasive of $0.63 \mathrm{~mm}$ fraction showed that all the roller pairs wore similarly in terms of quality. In contrast to the previous case, however, maximum mass loss is shown by the most ductile metal (experiment 1). Analysis of results of wearing by abrasive of $1 \mathrm{~mm}$ fraction is indicative of identical nature of wear of metal deposited with both the wires.

Working surface of rollers surfaced with Sv08G2S wire using ANK-18 flux (experiment 5) spalls off in the presence of abrasive particles (no spallation is found at testing without abrasive). Abrasive quartz particles with microhardness on the level of 10,000 MPa are embedded into roller surface layer, creating stress raisers in the form of pits, hairlines and scratches. At continued cyclic force load, the crack, caused by the above stress raisers, propagates fast.

Dependence of the ratio of lower and upper roller wear $\left(i_{1} / i_{\text {up }}\right)$ on their surface hardness ratio $\left(H B_{1} / H B_{\text {up }}\right)$ is of interest. Such a dependence for the case of wear without abrasive feeding is shown in Figure 1. It is characteristic that these dependencies have minimums for all the deposited metal compositions, and can be described by a parabolic function. 


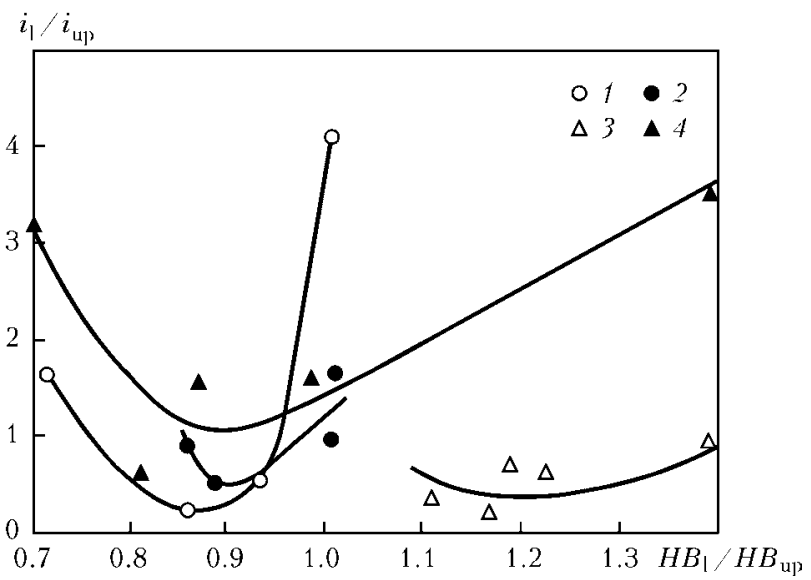

Figure 1. Dependencies of the ratio of roller wear $i_{1} / i_{\text {up }}$ and hardness $H B_{1} / H B_{\text {up }}$ at wear testing at metal-on-metal rolling friction without abrasive in surfacing with Sv-08G2S wire using ANK-19 (1) and ANK-18 (2) flux and in surfacing with Np-65 wire using ANK-19 (3) and ANK-18 (4) flux

For samples surfaced with Sv-08G2S wire using ANK-18 flux, minimum $i_{1} / i_{\text {up }}$ ratio is observed at $H B_{1} / H B_{\text {up }}$ ratio close to 0.85 . Similar wear of rollers $\left(i_{1} / i_{\mathrm{up}}=1\right)$ is recorded at hardness ratios of 0.75 and 0.95 . It is probable that in the first case wear of drive lower roller occurs by plastic shear (cut-off), and in the second case it results from brittle separation. Change of wear mechanism is manifested in all the considered cases.

At $H B_{1} / H B_{\text {up }}=1$, lower and upper roller wear ratio is equal to 3.7 and is indicative of a more intensive wear of drive roller.

It can be assumed that optimum ratio of wear values close to 0.25 at $H B_{1} / H B_{\text {up }}=0.85$ is achieved under the condition when both the rollers wear through elasto-plastic redeformation. This state can be regarded as a transition from tough to brittle fracture. Dependence $i_{1} / i_{\text {up }}=$ $=f\left(H B_{1} / H B_{\text {up }}\right)$ for layers, deposited with Sv08G2S wire using ANK-18 flux, is characterized by a narrow range of $H B_{1} / H B_{\text {up }}$ variation and the most probable mixed mechanism of roller wear. Hardness ratio, close to 0.9 , can be regarded as the optimum one. Equality of wear for both the rollers is achieved at hardness ratios of 0.85 and 0.98 .

A wide range of $H B_{1} / H B_{\text {up }}$ values is characteristic for metal deposited with Np-65 wire using ANK-18 flux. Optimum hardness ratio of 0.9 is in good agreement with earlier established values for metal deposited with Sv-08G2S wire. Characteristically, equality of roller wear is achieved only at optimum value of $H B_{1} / H B_{\text {up }}$ ratio. Layers, deposited with Np-65 wire using ANK-19 flux, differ from earlier considered ones by greater $H B_{1} / H B_{\text {up }}$ values and poorly defined optimum. It can be considered that the latter cor-

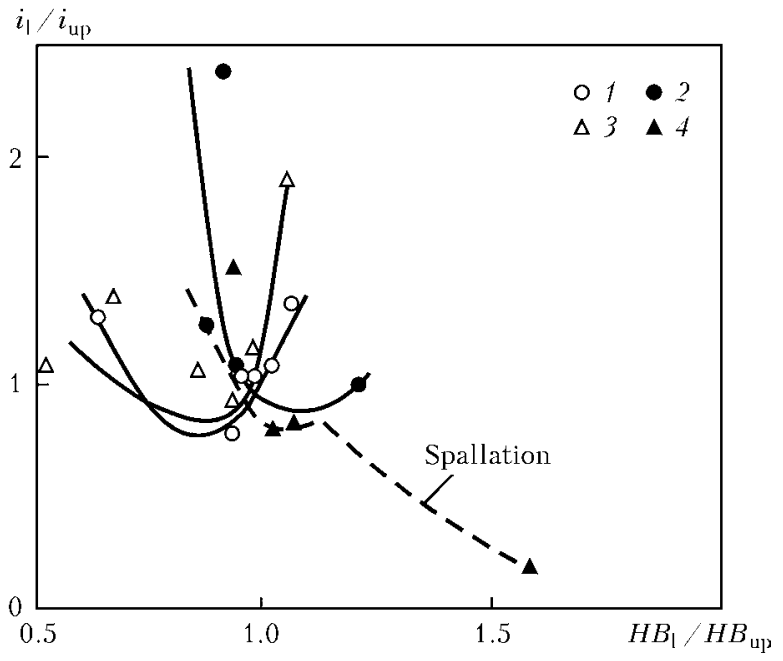

Figure 2. Dependencies of the ratio of roller wear $i_{1} / i_{\text {up }}$ and hardness $H B_{1} / H B_{\text {up }}$ at wear testing at metal-on-metal rolling friction with abrasive in surfacing with Sv-08G2S wire and AN-348A flux: 1 - abrasive from particles of fraction $d=0.315 ; 2-0.4 ; 3-0.63 ; 4-1 \mathrm{~mm}$

responds to hardness ratio of the order of 1.2. Here, wear value ratio is equal to $0.25-0.30$. Equality of wear values is possible at hardness ratio of about 1.4 .

Analyzing the derived dependencies and initial values of deposited metal hardness, it should be noted that at surfacing with $\mathrm{Sv}-08 \mathrm{G} 2 \mathrm{~S}$ wire using AN-348A and ANK-18 fluxes the lower rollers wear more intensively at equal hardness. This fact is attributable to leading role of lower roller at torque transmission and inevitable slipping of upper roller. The latter causes the higher degree of drive roller work-hardening that is confirmed experimentally.

Assuming $H B_{1} / H B_{\text {up }}=0.9$ hardness ratio as the optimum one, and considering the possibility of producing deposited metal layers of hardness from $H B 170$ up to $H B$ 547, the following recommendations can be made: at minimum hardness of upper sample ( $H B$ 170), optimum hardness of the lower one should be $H B 153$, at maximum hardness of upper sample ( $H B$ 547) it should be $H B 508$.

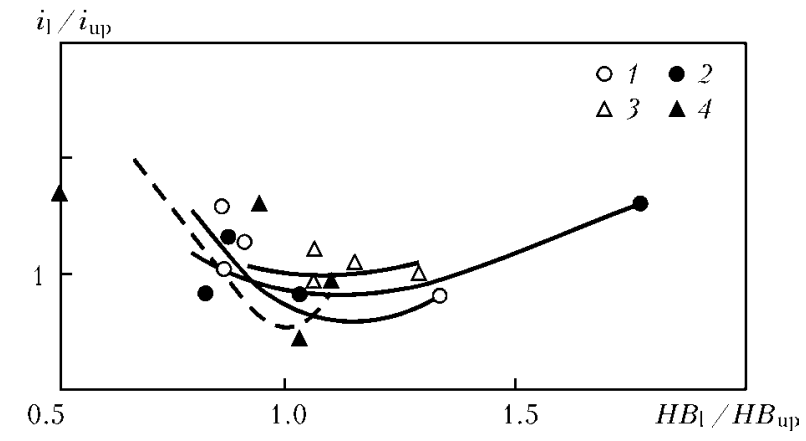

Figure 3. Dependencies of the ratio of wear $i_{1} / i_{\text {up }}$ and hardness $H B_{1} / H B_{\text {up }}$ of rollers surfaced with Np-45 wire and AN-348A flux at wear testing at metal-on-metal rolling friction with abrasive (designations are similar to Figure 2) 


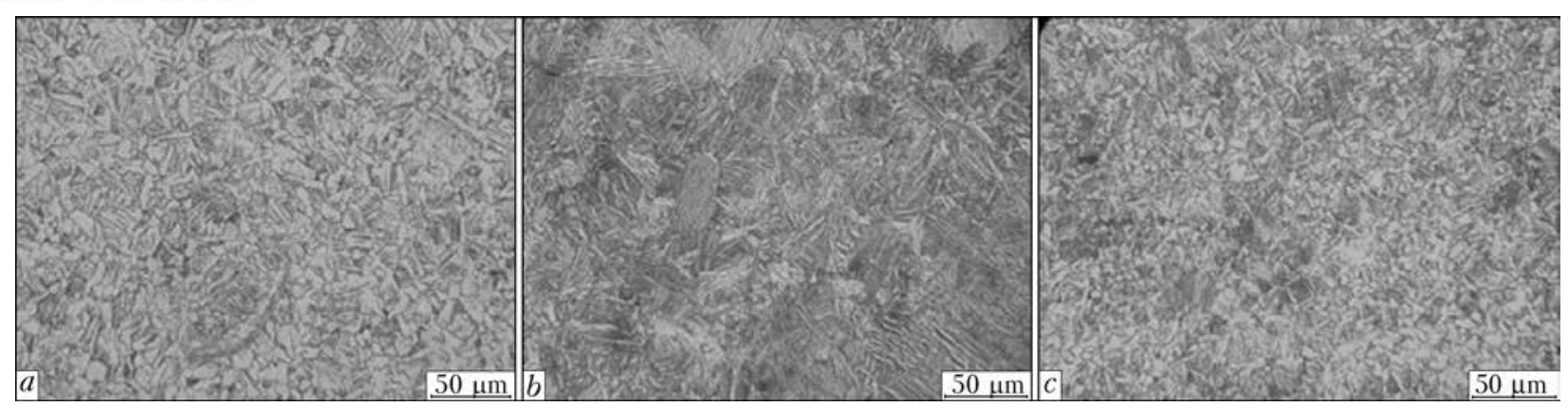

Figure 4. Microstructure of deposited metal providing higher wear resistance at contact with particles of $0.01-0.03(a)$, $0.31-0.80(b)$ and $0.81-1.20(c) \mathrm{mm}$

At abrasive testing of samples surfaced with Sv-08G2S wire using AN-348A flux (Figure 2), it was established that minimum value $i_{1} / i_{\text {up }}=$ $=0.6-0.7$ is found at optimum hardness ratio $\left(H B_{1} / H B_{\text {up }}=0.9\right)$ only at wearing by abrasive of 0.315 and $0.63 \mathrm{~mm}$ fraction. Wearing in the presence of abrasive of $0.4 \mathrm{~mm}$ fraction is characterized by shifting of optimum hardness ratio to values of 1.10-1.15. At application of abrasive of $1 \mathrm{~mm}$ fraction, minimum $i_{1} / i_{\mathrm{up}}$ value is reached at hardness ratio of 1.1 , at higher values macroscopic spallation of deposited metal is recorded.

At abrasive testing of samples surfaced with Np-65 wire using AN-348A flux (Figure 3), it is found that optimum hardness ratio is equal to $1.0-1.1$, that corresponds to $i_{1} / i_{\text {up }}=0.7-1.0$. No brittle fracture is observed. Thus, in order to minimize $i_{1} / i_{\text {up }}$ ratio it is necessary to ensure $H B_{1} / H B_{\text {up }}$ values on the level of $0.85-0.90$ for samples surfaced with Sv-08G2S wire, and 11.15 for samples surfaced with $\mathrm{Np}-65$ wire. In the presence of abrasive of $1 \mathrm{~mm}$ fraction at wearing of samples surfaced with $\mathrm{Sv}-08 \mathrm{G} 2 \mathrm{~S}$ wire, $H B_{1} / H B_{\text {up }}>1.2$ ratio should be avoided to prevent brittle fracture. Correlating the obtained experimental data on wearing intensity with deposited layer phase composition allows making the following recommendations.

At prevalence of finer $(0.01-0.30 \mathrm{~mm})$ abrasive, better wear resistance is provided by deposited metal having predominantly ferrite-pearlite structure (bainite fraction up to $5-10 \%)\left(\mathrm{Fi}^{-}\right.$ gure $4, a)$.

At increase of abrasive particle size (0.31$0.80 \mathrm{~mm}$ ), it is recommended to apply higher alloyed deposited metal with bainite-martensite structure (up to $5 \%$ fraction of martensite phase) (Figure $4, b$ ). In the case of prevalence of coarsegrained abrasive $(0.82-1.20 \mathrm{~mm})$, preference should be given to more ductile deposited metal with ferrite-pearlite structure (bainite fraction up to $10-20 \%$ ) (Figure $4, c$ ).

\section{Conclusions}

1. Correlation between abrasive fractional composition and deposited metal wear resistance was established.

At prevalence of fine $(0.01-0.30 \mathrm{~mm})$ abrasive, it is rational to deposit metal $(\%$ : $0.17 \mathrm{C}$; $2.35 \mathrm{Mn} ; 0.63 \mathrm{Si} ; 1.49 \mathrm{Cr} ; 0.09 \mathrm{Ni}$ ) having ferritepearlite structure with 5-10\% fraction of bainite. At increase of abrasive particle size (0.31$0.80 \mathrm{~mm}$ ), it is recommended to deposit higher alloyed metal (\%: 0.37C; $2.88 \mathrm{Mn} ; 0.39 \mathrm{Si}$; $3.18 \mathrm{Cr} ; 0.11 \mathrm{Ni})$ with bainite-martensite structure (up to $5 \%$ martensite phase fraction). In the case of prevalence of coarse-grained abrasive $(0.81-1.20 \mathrm{~mm})$, it is rational to deposit ductile ferrite-pearlite layers with bainite fraction of 10$20 \%(\%$ : $0.22 \mathrm{C} ; 2.09 \mathrm{Mn} ; 0.6 \mathrm{Si} ; 1.57 \mathrm{Cr} ; 0.13 \mathrm{Ni})$.

2. Hardness values and its value ratios for contacting deposited layers of parts are proposed, which are capable of increasing the part service life by 1.8 to 2.2 times under the condition of allowing for granulometric composition of abrasive flow.

1. Vinogradov, V.N., Sorokin, G.M., Kolokolnikov, M.G. (1990) Abrasive wear. Moscow: Mashinostroenie.

2. Lvov, P.N. (1970) Principles of abrasive wear resistance of road machine parts. Moscow: Strojizdat.

3. Livshits, L.S., Grinberg, N.A., Kurkumelli, E.G. (1969) Fundamentals of alloying of deposited metal. Moscow: Mashinostroenie.

4. Chigarev, V.V., Malinov, V.L. (2000) Selection of sparcely-alloyed surfacing materials for different impact-abrasive conditions. The Paton Welding J., 5, 55-57.

5. Mazel, Yu.A., Kuskov, Yu.V., Polishchuk, G.N. (1999) Classification of alloys on iron base for repair and strengthening surfacing. Svarochn. Proizvodstvo, 4, 35-38.

6. Balin, A.N., Berezovsky, A.V., Vishnevsky, A.A. et al. (2006) Surfacing consumables for hardening of parts operating under impact-abrasive wear conditions. The Paton Welding J., 2, 44-45.

7. (1974) Technology of fusion electric welding of metals and alloys. Ed. by B.E. Paton. Moscow: Mashinostroenie. 